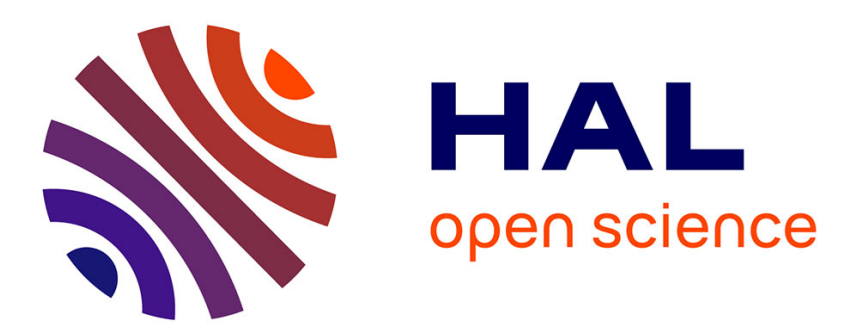

\title{
Comparative SERS study carried out on unsilanized and silanized oxidized porous silicon surface coated by small gold nanoparticles
}

\author{
Hamida Dridi, Adel Moadhen, Lazhar Mohamed Haji
}

\section{- To cite this version:}

Hamida Dridi, Adel Moadhen, Lazhar Mohamed Haji. Comparative SERS study carried out on unsilanized and silanized oxidized porous silicon surface coated by small gold nanoparticles. Journal of Porous Materials, 2015, 22 (November 2014), pp.1-7. 10.1007/s10934-014-9890-8 . hal-01095294

\author{
HAL Id: hal-01095294 \\ https://hal.science/hal-01095294
}

Submitted on 15 Dec 2014

HAL is a multi-disciplinary open access archive for the deposit and dissemination of scientific research documents, whether they are published or not. The documents may come from teaching and research institutions in France or abroad, or from public or private research centers.
L'archive ouverte pluridisciplinaire $\mathbf{H A L}$, est destinée au dépôt et à la diffusion de documents scientifiques de niveau recherche, publiés ou non, émanant des établissements d'enseignement et de recherche français ou étrangers, des laboratoires publics ou privés. 


\title{
Comparative SERS study carried out on unsilanized and silanized oxidized porous
}

\section{silicon surface coated by small gold nanoparticles}

\author{
H. Dridi ${ }^{1,2}$, A. Moadhen ${ }^{*}$, and L. Haji ${ }^{1}$
}

(1) Université Européenne de Bretagne, CNRS-UMR 6082, BP 80518, ENSSAT 6 rue Kerampont, 22305 Lannion Cedex, France

(2) Université de Tunis El Manar, Faculté des Sciences de Tunis, Unité Nanomatériaux et Photonique, 2092 El Manar-Tunis Tunisia.

*Corresponding Author, Email address: adel_moadhen@yahoo.fr

\begin{abstract}
Porous silicon (PSi) was formed by electrochemical anodization and was oxidized before silanization and immersion in colloidal gold nanoparticles $(5 \mathrm{~nm}$ size) solution. The oxidized PSi (OPSi) coated with nanoparticles was used as Surface Enhanced Raman Scattering (SERS) substrate, where Bovine Serum Albumin (BSA) was used as a target molecule. Also, Rhodamine 6G (R6G) dyes were used to confirm the SERS efficiency. Firstly, the bioconjugation between protein and gold nanoparticles (GNP) was investigated by Localized Surface Plasmon Resonance (LSPR) spectroscopy. Then a comparative SERS study from silanized and unsilanized OPSi was performed and showed a good vibrational BSA bands resolution with the unsilanized one. The silanized surface did not show any improvement on the SERS enhancement of the BSA due to the interferences between the vibrational modes of 3-aminopropyltriethoxysilane (APTES) and BSA. Furthermore, we have investigated the BSA solution $\mathrm{pH}$ effect on the SERS results in the case of unsilanized OPSi surface. The
\end{abstract}


results prove the efficiency of the SERS substrate at $\mathrm{pH}=4.9$, corresponding to BSA isoelectric point. A detection limit of about $10^{-8} \mathrm{M}$ was obtained for both BSA and R6G molecules.

Keywords: oxidized porous silicon, small size gold nanoparticles, SERS, Bovine Serum Albumin, Rhodamine 6G 


\section{Introduction}

Optical biosensor research based on Surface Enhanced Raman Scattering (SERS) effect has attracted a great attention. It has been demonstrated that SERS can provide scattering cross sections with several orders of magnitude higher than normal Raman spectroscopy [1]. As a result, ultra low concentration even at the scale of a single molecule was detected [2,3]. Raman amplification can be explained in terms of electromagnetic [4] and chemical enhancement [5]. The first effect involves the excitation of surface plasmon (or localized surface plasmon) at or close to resonance. While, the second effect was explained by a charge transfer between the metal surface and the adsorbed probe. Based on the excitation of the Localized Surface Plasmon (LSP), SERS has become an effective tool to analyze molecules. The metallic nanoparticles LSP frequency depends on the particle type (Au, Ag, $\mathrm{Cu} . .$.$) , size, shape [6,7]$ and as well as the refractive index of their surrounding medium, which in turn could have an influence on the SERS results [8].

Conventional SERS substrates have been often fabricated by depositing metallic nanoparticles on a planar surface [9-12]. Porous material based substrates could be interesting regarding their peculiar properties such as the large specific surface and the opened structure with pore size selective molecules filtering. Furthermore, Porous Silicon (PSi) based structures are promising for sensor application. This material was used as an efficient SERS template for various molecules detection like peptide, benzenethiol, organic molecules for different metals type [13-22]. Several parameters were studied such as porosity and thickness of the porous layer, metal nature, dipping time in the probe solution and the wavelength excitation to get the maximum of the SERS intensity [13-18]. It was reported that for PSi formed from $\mathrm{p}^{+}$type $\mathrm{Si}$, the best SERS result was obtained for high porosity, [19] while for n-type Si the opposite 
result was obtained [13]. This difference could be attributed to the difference in PSi morphology.

It was also reported that the metal deposition rate is related to the PSi formed from $\mathrm{n}$ or $\mathrm{p}$ type Si, which influences the detection limit value [23-24]. However and up to now, the number of publications interested on bio-molecules detection based on SERS PSi is still limited. In fact, PSi was used as a SERS substrate for some bio-molecules like horseradish peroxidase (HRP) and peptide. Giorgis et al [14] have showed a detectable concentration of HRP as low as $10^{-8}$ M. Specific complex peptide-antibody detection was performed by Virga et al., [25] which have also demonstrated a better SERS result using silver nanoparticles than silver thin film.

Furthermore, we have to mention, that surface functionalization process is interesting for some target molecules and for the metal deposition step, specifically in the case of colloidal metallic nanoparticles $[14,18,26]$. However, it was reported that SERS of Bovine Serum Albumin (BSA) on porous or planar substrates does not show an obvious amplification of the vibrational modes intensities [9,27]. Indeed, David et al [9] have demonstrated that optimizing the size $(170 \mathrm{~nm})$ and the shape of the lithographed gold nanocylinders lead to a SERS spectrum of BSA at low concentration $\left(10^{-4} \mathrm{M}\right)$.

In this work, we report a fabrication of a SERS-active substrate obtained by immersion of oxidized porous silicon (OPSi) in a small size $(5 \mathrm{~nm})$ colloidal gold nanoparticles (GNP) solution for the detection of BSA proteins and R6G molecules. Firstly, we have investigated the direct interaction between GNP and BSA to verify the bio-conjugation and to adjust the Raman excitation wavelength to the LSP band. Then, SERS results of BSA proteins from two types of OPSi surfaces (silanized and unsilanized) were compared. In this case, the effect of the surface functionalization on the SERS efficiency was discussed. We have also studied the 
BSA solution $\mathrm{pH}$ effect on the SERS response. The SERS substrate activity for BSA and R6G was obtained for concentrations as low as $10^{-8} \mathrm{M}$.

\section{Experimental}

\section{1-Preparation of functionalized oxidized porous silicon samples}

PSi samples were first elaborated by electrochemical anodization at room temperature and in the darkness of a highly $\mathrm{P}$ doped (100)-oriented silicon wafer having a resistivity of 3-7 $\mathrm{m} \Omega . c m$. The PSi was prepared by using a $20 \%$ aqueous-alcoholic hydrofluoric acid solution (1:2:2). The current density and the anodization time were $80 \mathrm{~mA} / \mathrm{cm}^{2}$ and 90 s respectively. After that, the PSi layers were oxidized for one hour in wet oxygen at $950^{\circ} \mathrm{C}$ to stabilize the surface [28-30] and also as a prerequisite step for the chemical functionalization [31,32]. By fitting the optical reflectivity data, we have obtained an estimated porosity of about $35 \%$. The OPSi layer thickness was equal to $4.8 \mu \mathrm{m}$ and the pore diameter was of around $30 \mathrm{~nm}$ (determined by Scanning Electron Microscopy).

OPSi surface could be activated by different silanization molecules (based on silanol groups) showing functional terminated groups (thiol, carboxyl, amines...). In our case, we have utilized 3-aminopropyltriethoxysilane (APTES) molecules. APTES molecules presented several functional amine terminals, which can enhance the GNP adsorption on the surface by electrostatic forces. Firstly, the OPSi samples were immersed in a $2 \%$ hydro-alcoholic APTES solution (methanol- deionised water $(\mathrm{v} / \mathrm{v})$ ) for 20 minutes. After rinsing with deionised water (18 M $\Omega$ ) and drying under with nitrogen flux $\left(\mathrm{N}_{2}\right)$, the samples were heated at $100^{\circ} \mathrm{C}$ in air to remove the solvent traces from the pores. Also and for comparison, some samples without silanization were used in this work. 


\section{2- Fabrication of the SERS-active substrate}

The spherical GNP deposition was carried out by the immersion of the silanized and unsilanized OPSi surfaces in a colloidal solution of a mono-disperse GNP ( $5 \mathrm{~nm}$ size) for three hours. The small size of GNP could promote their infiltration inside the pores. The samples were then rinsed with deionised water $(18 \mathrm{M} \Omega)$ and dried with $\mathrm{N}_{2}$. Finally, the samples were incubated at $80^{\circ} \mathrm{C}$ for $30 \mathrm{~min}$ to remove the solvent traces from the pores.

In this study, elaborated samples were incubated in an aqueous solution (for different $\mathrm{pH}$ ) of a Bovine Serum Albumin (BSA) protein, for 2 days at room temperature. BSA is a protein with a $66.4 \mathrm{kDa}$ molecular weight and it contains 583 amino acids.

In addition, GNP coated OPSi surfaces were immersed in an aqueous Rhodamine 6G (R6G) solution for $20 \mathrm{~min}$.

GNP colloidal solution, APTES, R6G and BSA were purchased from Sigma Aldrich and used without further purification.

\section{3- Instrumentation}

UV-Vis-NIR absorption spectra were recorded using a Perkin Elmer spectrophotometer lambda 900. The optical system is equipped with a deuterium lamp and a monochromator (wavelength range 200-2000 nm). The system resolution is of about $1 \mathrm{~nm}$. The AFM scanner (Digital Instruments Nanoscope) was mounted on the sample stage and imaged in tapping mode. The Raman scattering measurements were performed at room temperature on a MicroRaman system HORIBA Jobin Yvon (LabRAM HR800). The BSA measurements were carried out using an Argon laser excitation $488 \mathrm{~nm}$ with a power at the sample surface equal to $47 \mathrm{~mW}$. The excitation was chosen as the closest one to the $5 \mathrm{~nm}$-GNP LSP band. The 
experiments with R6G were carried out using an He-Ne laser excitation $632.8 \mathrm{~nm}$ with a power at the surface less than $1 \mathrm{~mW}$. This wavelength is more suitable for the study of R6G to avoid its fluorescence. The spectrometer resolution is equal to $1 \mathrm{~cm}^{-1}$. A CCD camera was used to record Raman spectra. Data were collected with an integration time of a few tens of seconds and the intensities were calculated with the unit of counts per second (cps). All Raman and SERS spectra presented in this paper were averaged from five locations on each sample. Some of the Raman spectra were smoothed and we have done the base line.

\section{Results and discussion}

In Fig.1 we report the absorption spectra of the various solutions of colloidal GNP and GNPBSA conjugate. The GNP's Plasmon band is localized at $523 \mathrm{~nm}$ which is related to the collective free electron oscillation on the surface of the GNP (Localized Surface Plasmon Resonance: LSPR). The BSA's absorption band is located at $279 \mathrm{~nm}$. After adding BSA molecules to GNP, we notice a red shift of $\delta \lambda_{1}=4 \mathrm{~nm}$ and a decrease of the integrated intensity of the LSPR band. Such modification could be related to a change of the refractive index of the surrounding medium of the GNP and/or molecular interactions. In addition, the BSA absorption band showed a blue shift of $\delta \lambda_{2}=3 \mathrm{~nm}$ which is an evidence of some GNPBSA bio-conjugation. It is known that the BSA conformation and its net charge depend on $\mathrm{pH}$ value. The $\mathrm{pH}$ modification could influence the absorption band position and the interaction types with GNP [33]. In our case, no changes of the LSP frequency were observed for three pH BSA solutions $(3.3,4.9$ and 6.9). This result is not consistent with the fact that we should observe a significant shift in the case where the BSA charge is suitable for electrostatic interaction with GNP. 


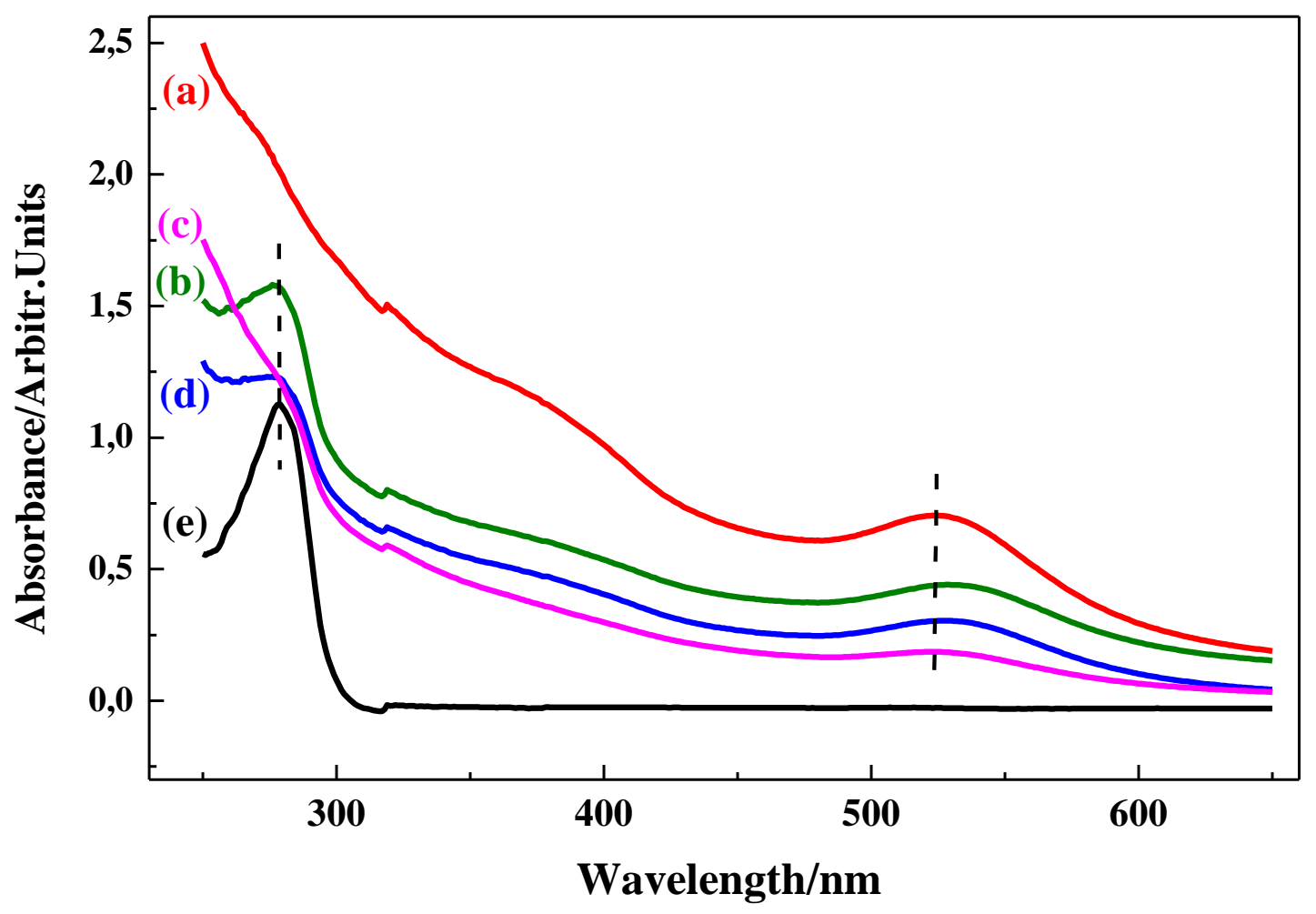

Figure 1: Absorption spectra of colloidal GNP, BSA ( $10^{-5} \mathrm{M}$ concentration) solution and GNP-BSA conjugate for various BSA pH. GNP (5 nm) (a), GNP-BSA (pH=3.3) (b), GNP-BSA (pH=4.9) (c), GNP-BSA (pH=6.9) (d) and BSA (pH=3.3) (e).

In Fig. 2, we present the topographic AFM images of OPSi, after GNP deposition (GNPOPSi) and after BSA grafting (BSA-GNP-OPSi). The AFM image, in figure 2.b, reveals a small surface roughness variation of the OPSi after GNP deposition. This is probably due to, very low gold nanoparticles concentration $\left(5.510^{13} \mathrm{~mL}^{-1}\right)$ in the colloidal solution. After grafting BSA (figure 2.c), the AFM image did not show an obvious change of the surface roughness. However, we noticed the presence of some agglomeration on the surface (the 
regions surrounded with dashed circles), which could be attributed to the residual BSA molecules after rinsing.

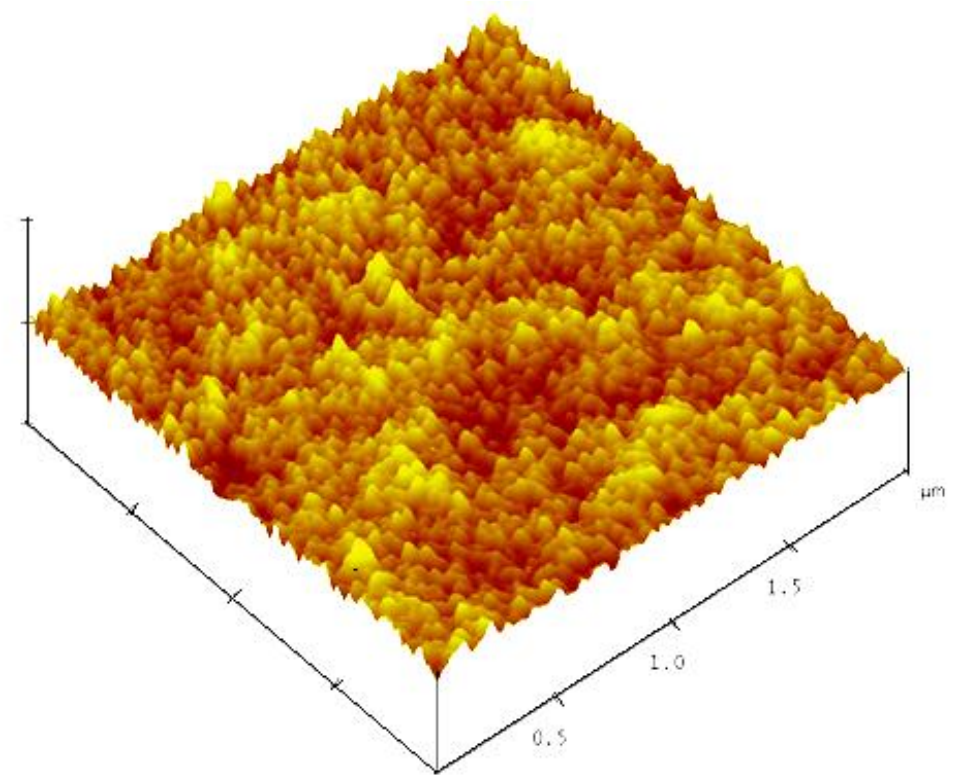

(a)

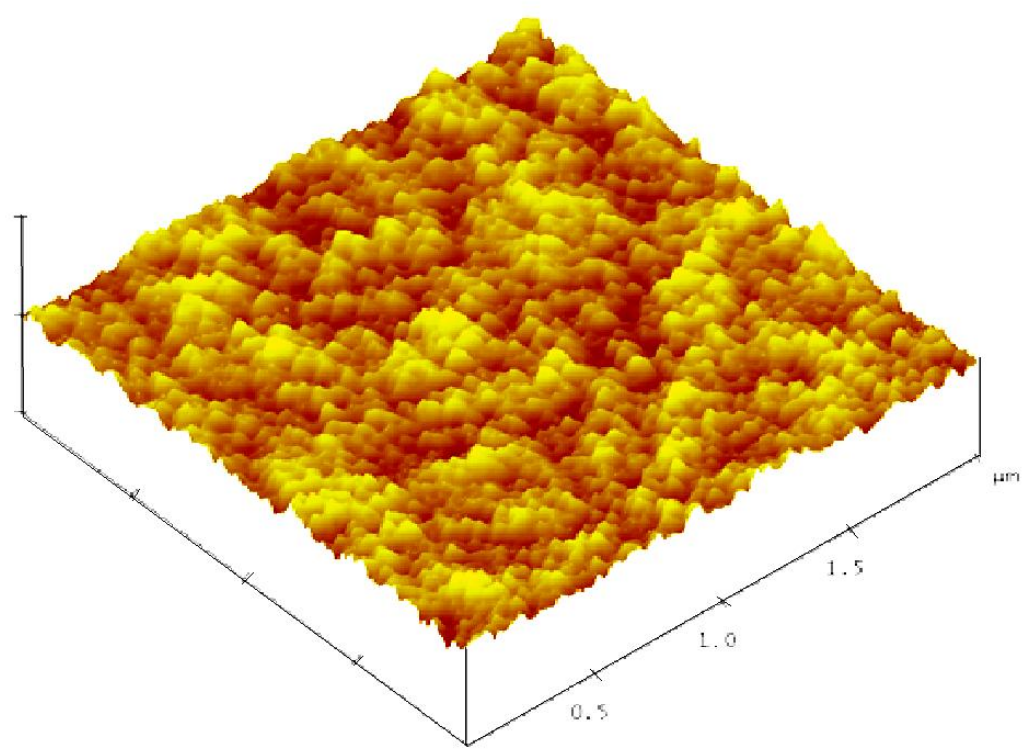

(b) 


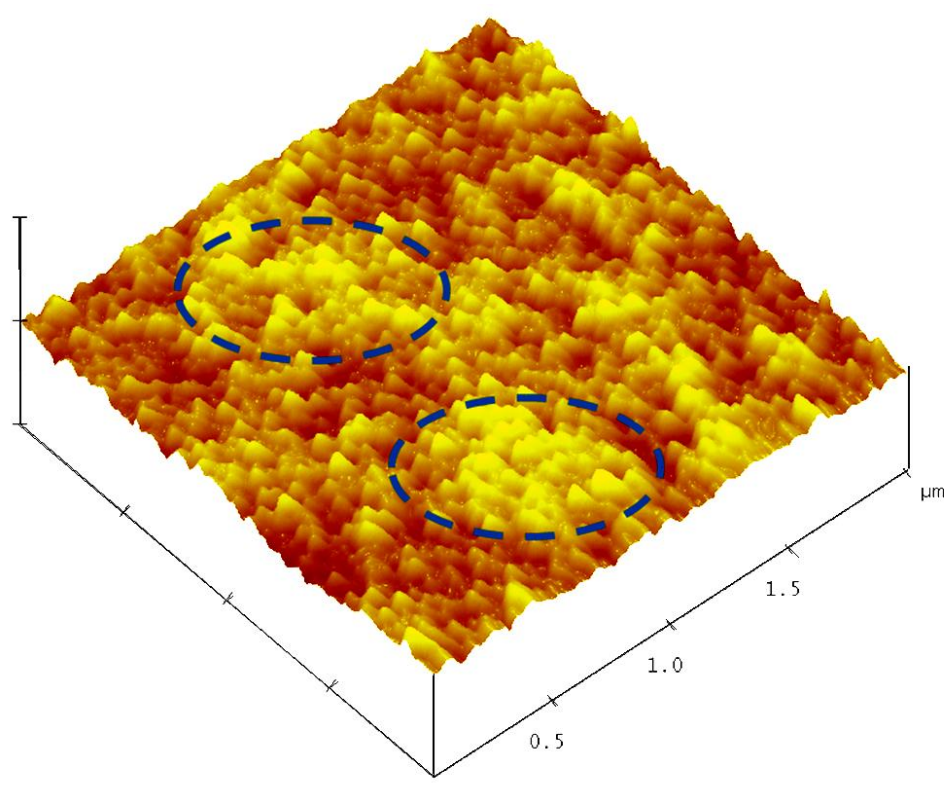

(c)

Figure 2: AFM images corresponding to a) OPSi, b) GNP-OPSi and c) BSA-GNP-OPSi.

Dashed circles correspond to BSA residue.

Raman and SERS measurements were performed on such silanized OPSi substrate as well as on unsilanized one, for comparison. Silanization step was supposed to give a homogeneous distribution of gold nanoparticles [34]. Since GNP were assumed to be attached on the silanized surface via electrostatic bonds with the amines terminals of APTES molecules. However, the effect of the functionalization process depends on the metal deposition way and the substrate type (glass, porous materiel, rough substrate...).

Fig. 3 shows the Raman and SERS spectra of BSA at $10^{-6} \mathrm{M}$ concentration in the case of silanized substrate. In Fig. 3-a, Raman spectrum of BSA shows the appearance of some vibrational modes, e.g, the amide I which is located at $1660 \mathrm{~cm}^{-1}$ [35]. However, this result was hardly obtained from some regions, which we have attributed to a low adsorbed BSA 10 
and/or a strong homogeneity of the adsorbed molecules. The large band between 1400-1500 $\mathrm{cm}^{-1}$ could correspond to the contribution of the $v\left(\mathrm{CH}_{2}\right)_{\text {def }}\left(1450 \mathrm{~cm}^{-1}\right)$ and $v(\mathrm{C}-\mathrm{N})\left(1412 \mathrm{~cm}^{-1}\right)$ modes assigned to either BSA and APTES molecules [31]. However, after BSA grafting, the intensity of these bands decreased drastically. We assumed that after rinsing, BSA molecules not linked to APTES molecules were almost removed. Thus, this intensities decrease, can be an indication of the BSA molecules attachment strength.

In Fig. 3 (b-c), we report the SERS spectra before and after BSA grafting. Compared to the spectrum discussed above, the main vibrational modes intensities are clearly amplified. After GNP deposition, this amplification corresponds to the APTES modes and is attributed to a GNP LSPR effect. Also, we observe an increase of the vibrational modes intensities located at $1450 \mathrm{~cm}^{-1}$ and $1350 \mathrm{~cm}^{-1}$ after adding the proteins. However, the SERS effect is not as efficient as for APTES molecules.

Moreover, no clear BSA signature was observed in this case (amide I $\left(1660 \mathrm{~cm}^{-1}\right)$, amide II $\left(1550 \mathrm{~cm}^{-1}\right)$ and amide III $\left.\left(1260 \mathrm{~cm}^{-1}\right)\right)$. To quantify this result, we have calculated the integrated intensity for the $1450 \mathrm{~cm}^{-1}$ mode from SERS (after subtraction of the signal at GNP step) and Raman spectra. Thanks to the contribution of the GNP, the integrated intensity of $v\left(\mathrm{CH}_{2}\right)$ mode of the BSA is amplified 2 times. 


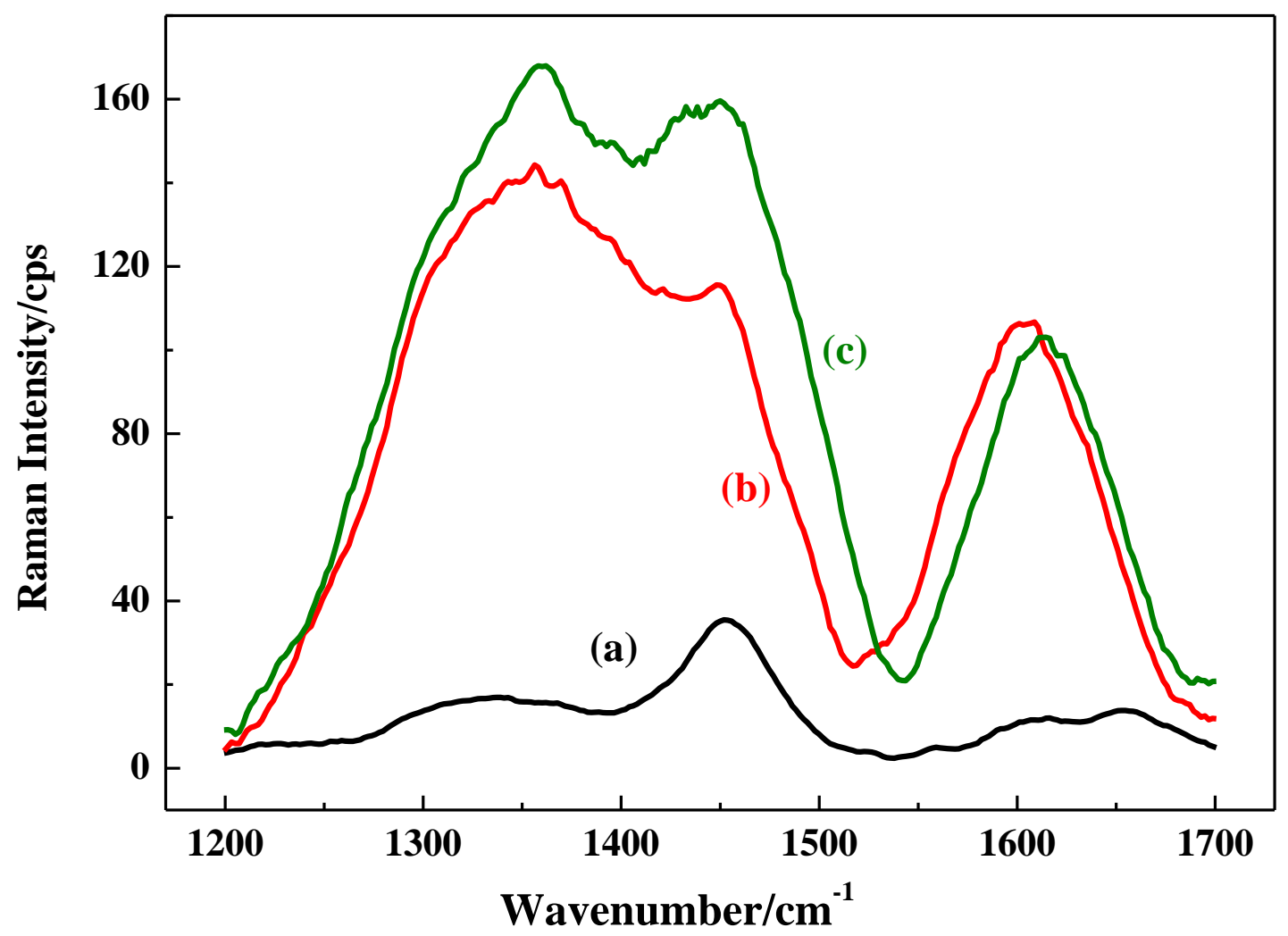

Figure 3: Raman spectrum of BSA $\left(10^{-6} \mathrm{M}\right) / \mathrm{APTES} / \mathrm{OPSi}(\mathrm{a})$ and SERS spectra of GNP/APTES/OPSi (b) and BSA $\left(10^{-6} \mathrm{M}\right) / \mathrm{GNP} / \mathrm{APTES} / \mathrm{OPSi}$ (c).

A silanized substrate permits us to obtain a good homogeneity of SERS results but without a good resolution of BSA's specific bands (for instance amide I). BSA modes are located in quite the same frequency region than those of APTES. Thus, it is very difficult to distinguish the vibrational modes of BSA and APTES molecules. To avoid this, one can look for a well adapted functionalized process for instance by choosing a silanization molecule having a different signature than that of BSA protein. This manner could be a rather complicated process. So, we have chosen an unsilanized substrate and GNP were directly deposited on the 
OPSi substrate. In this case, we can suspect a weak interaction between GNP and hydroxyls terminals of the OPSi substrate surface.

Figures 4-a, 4-b show Raman and SERS spectra of BSA at $10^{-6} \mathrm{M}$ concentration at a $\mathrm{pH}=6.9$ in the range of $1100-1800 \mathrm{~cm}^{-1}$ and $2600-3200 \mathrm{~cm}^{-1}$, respectively. SERS spectra show clearly the BSA signature, through the vibrational modes corresponding to amide II $\left(1550 \mathrm{~cm}^{-1}\right)$, amide $\mathrm{I}\left(1660 \mathrm{~cm}^{-1}\right),-\mathrm{C}=\mathrm{O}\left(1730 \mathrm{~cm}^{-1}\right)$ and $\mathrm{C}-\mathrm{H}$ stretching mode (in the range of 2800-3030 $\mathrm{cm}^{-1}$ ) [36], while Raman spectra show a weak signal of BSA molecules in $2800-3030 \mathrm{~cm}^{-1}$ and no detectable signal of BSA in the range $1100-1800 \mathrm{~cm}^{-1}$. This result proves the efficiency of the SERS substrate based on OPSi to obtain a high sensitivity detection of BSA protein for a $\mathrm{pH}=6.9$.

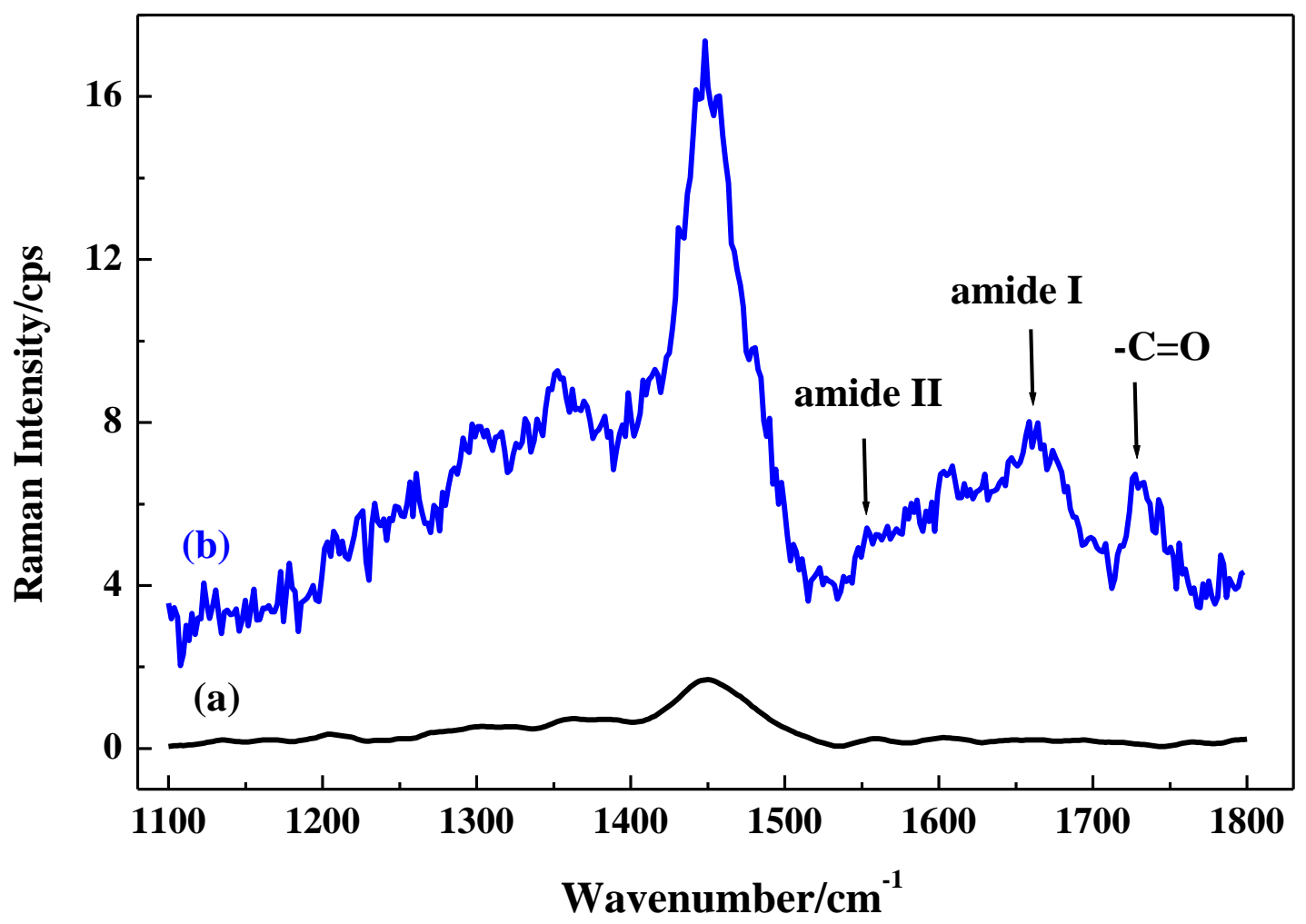

Figure 4-a: Raman spectrum of BSA $\left(10^{-6} \mathrm{M}\right) / \mathrm{OPSi}$ (a) and SERS spectrum of BSA $\left(10^{-6} \mathrm{M}\right) / \mathrm{GNP} / \mathrm{OPSi}(\mathrm{b})$ at $\mathrm{pH}=6.9$ in the $1100-1800 \mathrm{~cm}^{-1}$ wavelength range. 


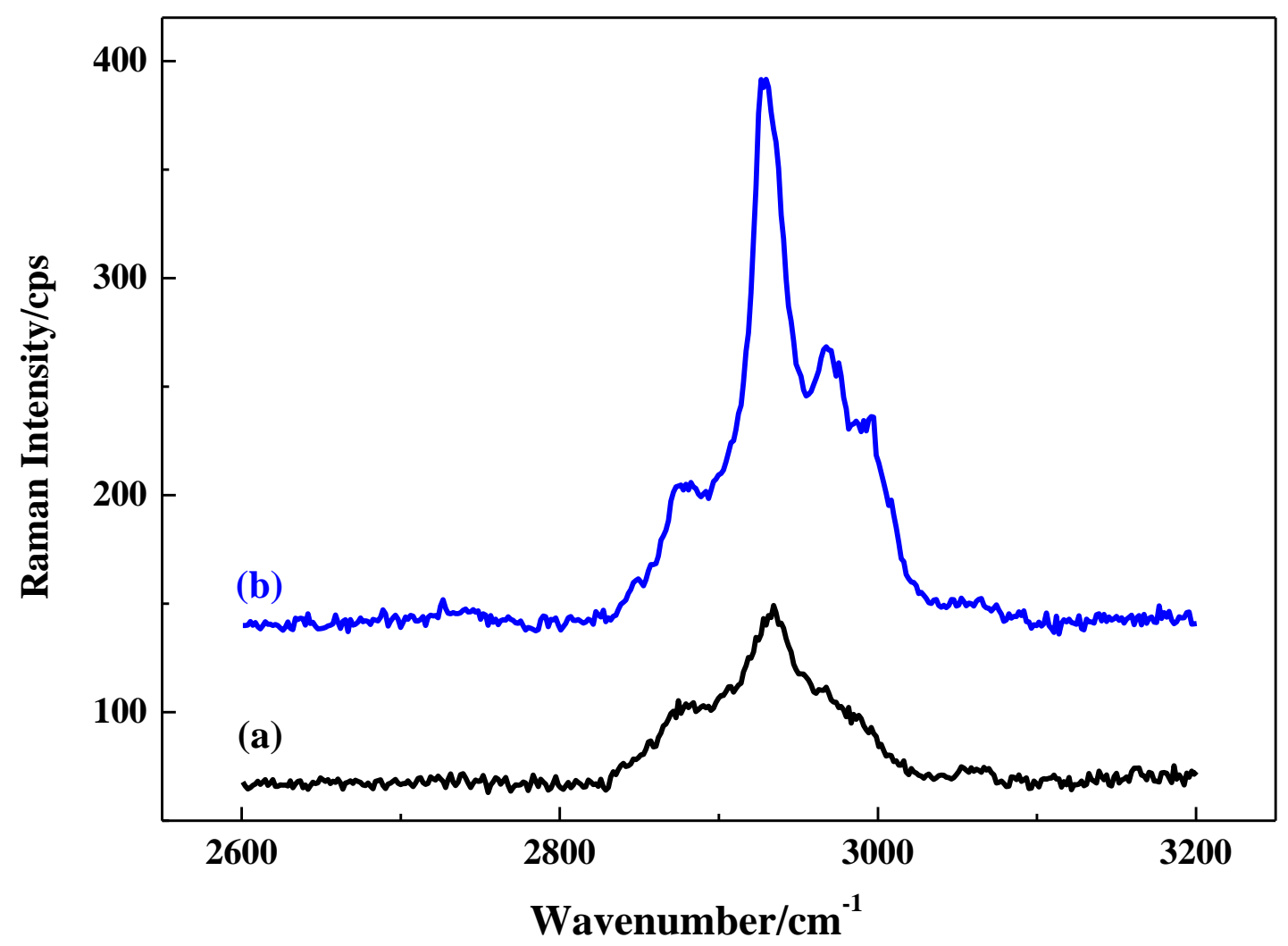

Figure 4-b: Raman spectrum of BSA $\left(10^{-6} \mathrm{M}\right) / \mathrm{OPSi}$ (a) and SERS spectrum of BSA $\left(10^{-6} \mathrm{M}\right) / \mathrm{GNP} / \mathrm{OPSi}(\mathrm{b})$ at $\mathrm{pH}=6.9$ in the $2600-3200 \mathrm{~cm}^{-1}$ wavelength range.

In order to analyze the degree of grafting of the BSA molecules in the pores of the OPSi, we followed the evolution of the C-H mode of BSA, deduced from the Raman spectra recorded in volume. Figure 5 shows SERS spectra of BSA protein at different depths on the cross section of the OPSi. The in-depth Raman measurements shows an enhancement of the signal of BSA modes at the middle $(\mathrm{z}=2-3 \mu \mathrm{m})$ of the layer. This indicates that BSA molecules are deeply incorporated into the OPSi layer and it may take places over all the pore walls. 


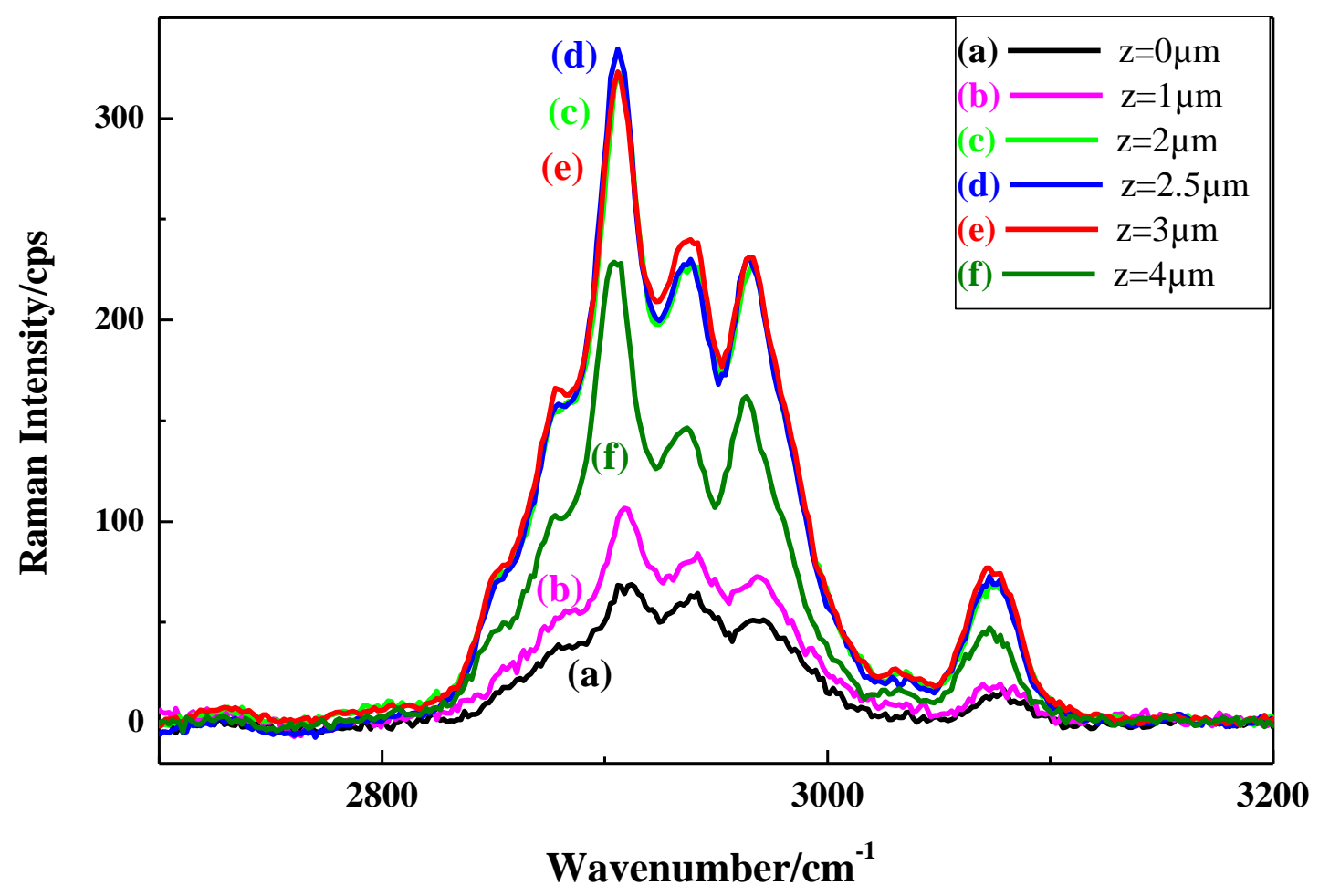

Figure 5: In-depth SERS spectra of BSA/GNP/OPSi in the $2700-3200 \mathrm{~cm}^{-1}$ wavelength range. $\mathrm{BSA}$ concentration $=10^{-6} \mathrm{M}$ at $\mathrm{pH}=4.9$.

It has been reported, that the net charge of BSA and its conformation, strongly depend on its solution $\mathrm{pH}$ [37]. The BSA iso-electric point (pI), where the protein is electrically neutral, is between 4.6-4.8 [38]. Thus, the adsorption of BSA molecules on the OPSi surface should be different for various $\mathrm{pH}$ (below and above the $\mathrm{pI}$ ). So, we have studied the BSA pH effect (3, 4.9 and 6.9) on the SERS signal, in the case of unsilanized substrate.

The results are reported in Fig. 6 and show high SERS intensities at a pH close to the pI (4.9). So, we can deduce that BSA molecules were easily adsorbed on the substrate surface. In addition, we have obtained a better result for a $\mathrm{pH}=3$ than for a $\mathrm{pH}=6.9$. This could be 
probably related to the net positive charge of the protein at a $\mathrm{pH}$ lower than $\mathrm{pI}$, which improves the interactions with GNP via citrate sodium.

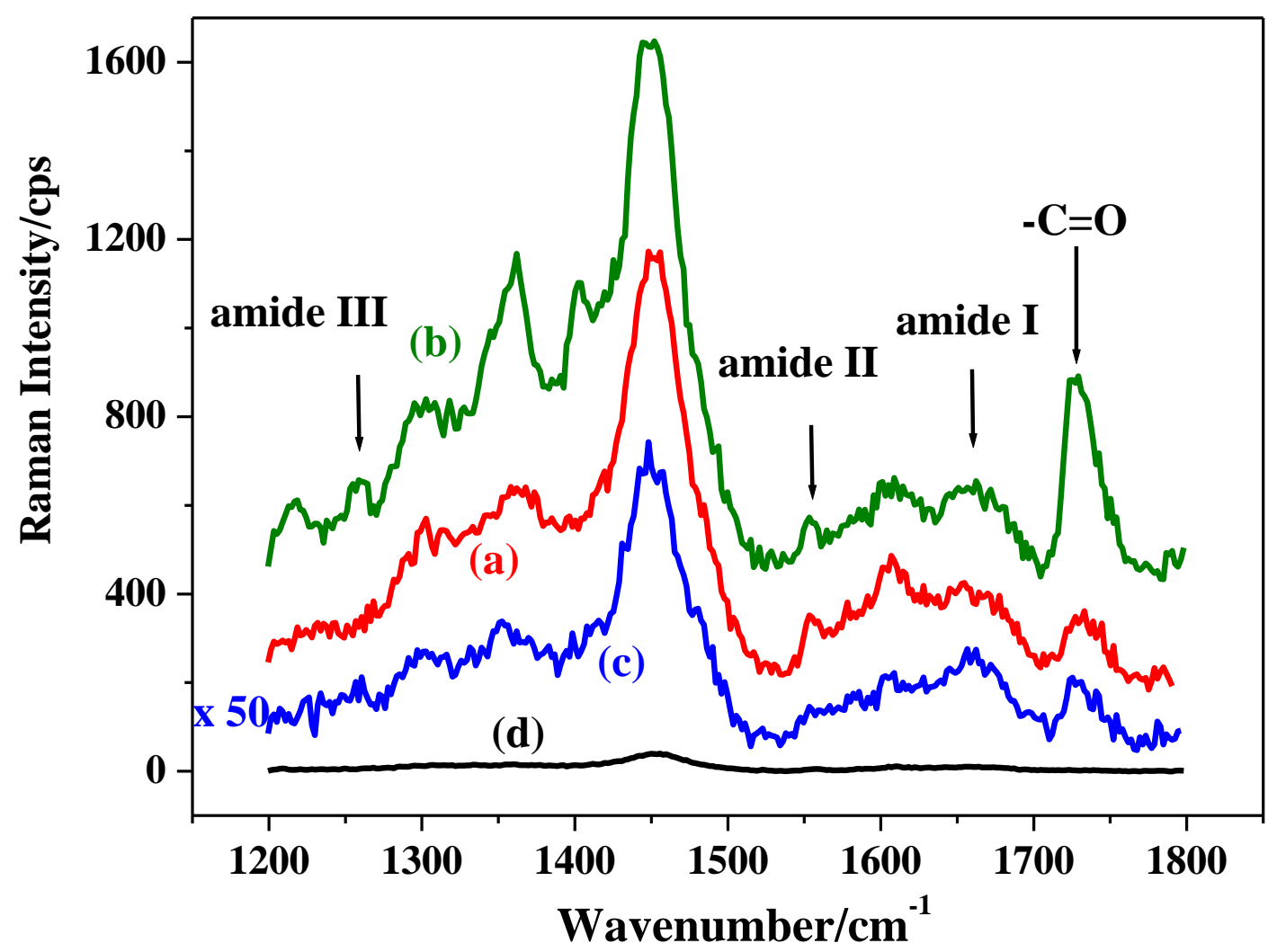

Figure 6: SERS spectra of BSA $\left(10^{-6} \mathrm{M}\right) / \mathrm{GNP} / \mathrm{OPSi}$ at $\mathrm{pH}=3(\mathrm{a}), \mathrm{pH}=4.9$ (b) and $\mathrm{pH}=6.9$

(c) and Raman spectrum of BSA $\left(10^{-6} \mathrm{M}\right) / \mathrm{OPSi}$ at $\mathrm{pH}=4.9$ (d).

As a proof of the efficiency of our SERS substrate for a $\mathrm{pH}=4.9$, we have also reported in Fig.6 the Raman signal of $10^{-6} \mathrm{M}$ BSA molecules. We can see, clearly, the enhancement of all vibrational modes associated to the protein.

In order to estimate the limit of detection (LOD), we have varied the BSA concentration from $10^{-6} \mathrm{M}$ down to $10^{-8} \mathrm{M}$ and recorded their SERS spectra in the case of unsilanized substrate and for a $\mathrm{pH}$ solution equal to 4.9. As it can be seen in Fig. 7, almost all the vibrational bands 
are visible even at the lowest concentration. However, the band at $1730 \mathrm{~cm}^{-1}$ become indistinguishable, thus we assume that the LOD is up to $10^{-8} \mathrm{M}$. This LOD value is four orders of magnitude lower than those obtained by other authors for BSA molecules $[9,27]$. This improvement could be related to combined effects of the large surface area of the porous silicon and the small nanoparticles size confined within the pores. Since, the GNP number is low $\left(55 \mathrm{GNP} / \mu \mathrm{m}^{3}\right)$, it's very difficult to experimentally demonstrate the role of the internal surface of the porous layer.

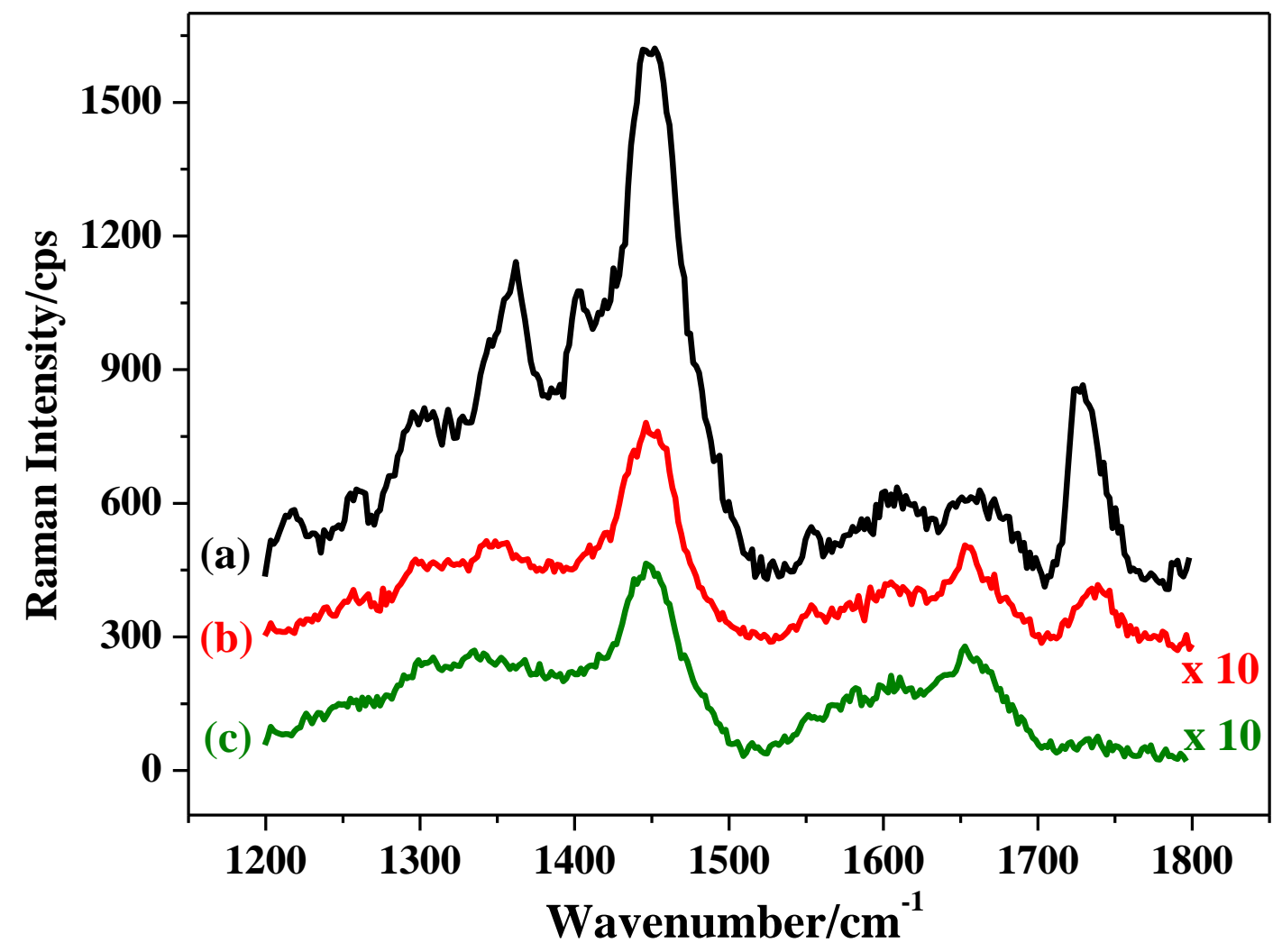

Figure 7: SERS spectra of BSA at $\mathrm{pH}=4.9$ for $10^{-6} \mathrm{M}$ (a) $10^{-7} \mathrm{M}$ (b) and $10^{-8} \mathrm{M}$ (c).

In the other hand and in the goal to verify the efficiency of our SERS substrate, we have used Rhodamine 6G (R6G) molecules. R6G molecules well known to give a high SERS signal, as 
the other dyes molecules (crystal violet, cyanine...) [25, 27]. Fig. 8 shows the SERS spectrum of unsilanized $\mathrm{R} 6 \mathrm{G}$ at $10^{-8} \mathrm{M}$ concentration. As it can be seen, among the vibrational features, we observed some typical R6G modes at 1128, 1198, 1312, 1356, 1503, 1599 and $1639 \mathrm{~cm}^{-1}$ corresponding to $\mathrm{C}-\mathrm{H}$ in-plane bend, $\mathrm{C}-\mathrm{C}$ stretching, aromatic $\mathrm{C}-\mathrm{C}$ stretching, $\mathrm{C}-\mathrm{N}$ stretching, aromatic $\mathrm{C}-\mathrm{C}$ stretching, aromatic $\mathrm{C}-\mathrm{C}$ stretching and aromatic $\mathrm{C}-\mathrm{C}$ stretching, respectively [27]. For comparison, R6G normal Raman spectrum correspond to a $10^{-6} \mathrm{M}$ shows just the presence of two vibrational bands located at 1360 and $1508 \mathrm{~cm}^{-1}$ with a very low intensity. In our case, the obtained detection limit of R6G molecules is $10^{-8} \mathrm{M}$. Finally, we can conclude that OPSi is a promising SERS substrate for chemical and biological molecules detection at low concentrations.

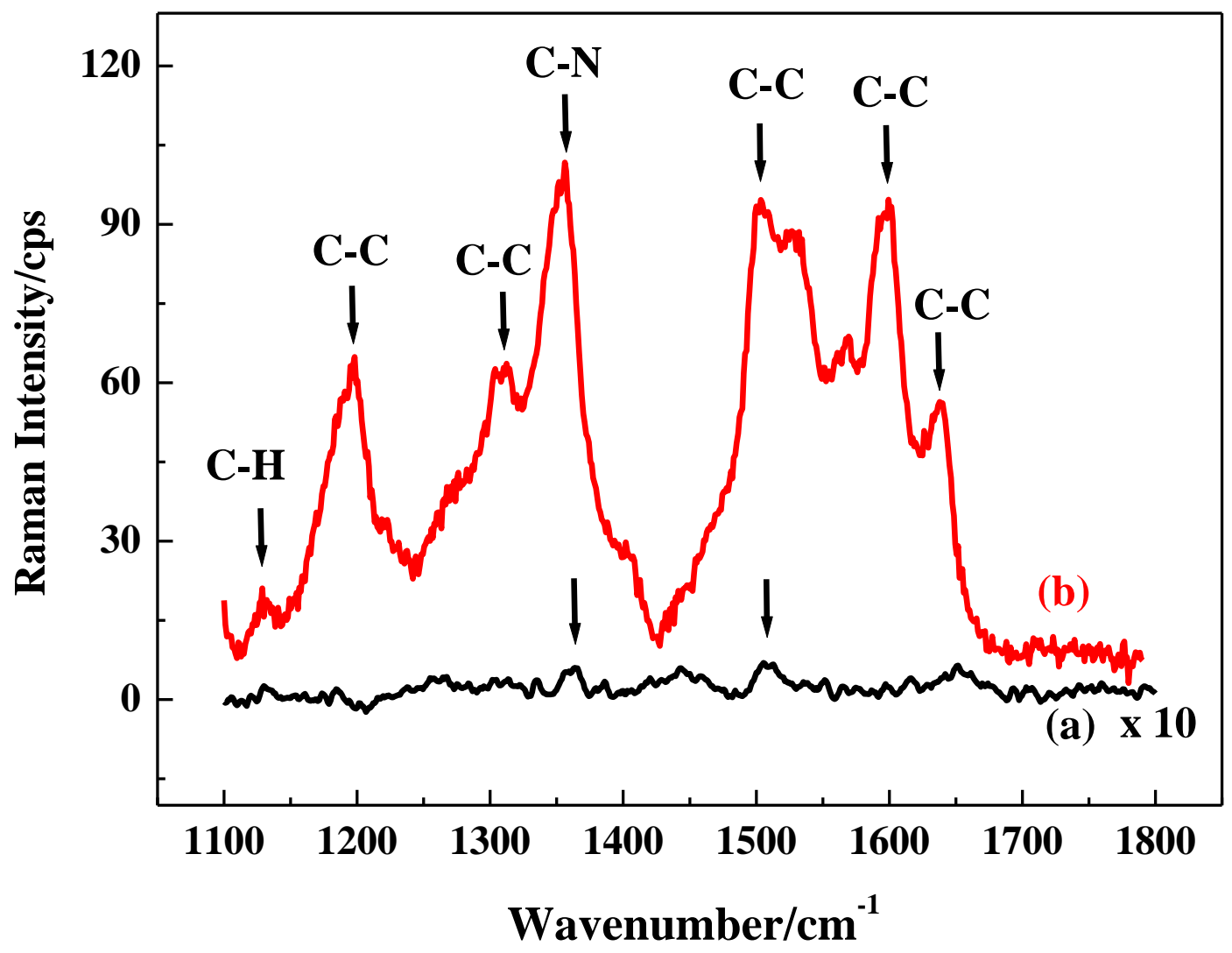

Figure 8: Raman of R6G $\left(10^{-6} \mathrm{M}\right) / \mathrm{OPSi}$ (a) and SERS of R6G $\left(10^{-8} \mathrm{M}\right) / \mathrm{GNP} / \mathrm{OPSi}$ (b). 


\section{Conclusion}

SERS based porous silicon substrate represents a viable approach for chemical and biological molecules detection. Spherical gold nanoparticles with small size $(5 \mathrm{~nm})$ were used to reveal a significant SERS effect for either BSA proteins and R6G molecules at $10^{-8} \mathrm{M}$ concentration. We have obtained a better BSA modes resolution in the case of unsilanized OPSi than the silanized one. Although, it has been noted that silanization allows the improvement of target molecule concentration binding on the surface via stronger interaction and it permits also to obtain an homogeneous SERS signal. In our case, the luck of resolution of BSA modes obtained on the silanized substrate could be explained by the interferences between the vibrational modes of APTES and BSA proteins. Furthermore, we have demonstrated that SERS results depend on BSA pH solution. A strong BSA SERS intensity at $\mathrm{pH}=4.9$, corresponding to the iso-electric point of BSA, was obtained.

\section{Acknowledgment}

The authors thank the Franco-Tunisian Joint Committee of University Cooperation (CMCU), No. 11G1109 PHC-Utique project for its support and financial of a part of this work.

\section{References}

[1] M. Fleischmann, P. J. Hendra, and A. Mcquillan, J. Phys. Chem. Lett. 26 (2) (1974) 163.

[2] P. Alivisatos, Nature Biotech. 22 (1) (2004) 47.

[3] K. Kneipp, Y. Wang, H. Kneipp, L. T. Perelman, I. Itzkan, R. R. Dasari and M. S. Feld, Phys. Rev. Lett. 78 (9) (1997) 1667. 
[4] G. Tourrel, J. Corset, Raman Microscopy: Developments and Applications, Elsevier Academic Press, San Diego, California USA 1996, 92101.

[5] A. Otto, Phys. Stat. Sol. (a) 188 (4) (2001) 1455.

[6] M. Iosin, F. Toderas, P.L. Baldeck, S. Astilean, J. Mol. Struct. 196 (2009) 924.

[7] J. Hu, Z. Wang and J. Li, Sensors 7 (12) (2007) 3299.

[8] E. N. Esenturk and A. R. H Walker, J. Raman Spectrosc. 40 (1) (2009) 86.

[9] C. David, N. Guillot, H. Shen, T. Toury and M. Lamy de la Chapelle, Nanotechnology 21 (2010) 475 .

[10] G. Das, F. Mecarini, F. Gentile, F. De Angelis, M. Kumar HG, P. Candeloro, C. Liberale, G. Cuda, E. Di Fabrizio, Biosens. Bioelect. 24 (2009) 1693.

[11] K. Fujiwara. H. Watarai. H. Itoh. E. Nakahama. N. Ogawa, Anal. Bioanal. Chem. 386 (3) (2006) 639.

[12] N. Nath, A. Chilkoti, Anal. Chem. 74 (2002) 504.

[13] A. Y. Panarin, S.N. Terekhov, K.I. Kholostov, V.P. Bondarenko, Appl. Surf. Sci. 256 (2010) 6969.

[14] F. Giorgis, E. Descrovi, A. Chiodoni, E. Froner, M. Scarpa, A. Venturello, F. Geobaldo, Appl. Surf. Sci. 254 (2008) 7494.

[15] M.V. Chursanova, L.P. Germash, V.O. Yukhymchuk, V.M. Dzhagan, I.A. Khodasevich, D. Cojoc, Appl. Surf. Sci. 256 (2010) 33693. 
[16] T. Ignat, R. Munoz, K. Irina, I. Obieta, M. Mihaela, M. Simion, M. Iovu, Superlattices and Microstructures 46 (2009) 451.

[17] W. F. Jiang, X. F. Li, H. T. Cai, X. J. Li, Appl. Surf. Sci. 257 (2011) 8089.

[18] Y. Jiao, D. S. Koktysh, N. Phambu, and Sharon M. Weiss. Appl. Phys. Lett. 97 (2010) 153125.

[19] S. Chan, S. Kwon, T.W. Koo, L. P. Lee and A. A. Berlin, Adv. Mater. 15 (19) (2003) 1595.

[20] Y. Lai, J. Wang, T. He, S. Sun, Analytical Letters 47 (2014) 833.

[21] C. Lü, J. Wang, X. Lü, Z. Jia, Chinese Optics Letters 12 (2014) S12401.

[22] X. Sun, N. Wang, H. Li, Appl. Surf. Sci. 284 (2013) 549.

[23] A.Y. Panarin, V.S. Chirvony, K.I. Kholostov, P.-Y. Turpin, S.N. Terekhov, J. Appl. Spectrosc. 76 (2009) 280.

[24] T. Tsuboi, T. Sakka, Y. H. Ogata, Appl. Surf. Sci. 147 (1999) 6.

[25] A. Virga, P. Rivolo, E. Descrovi, A. Chiolerio, G. Digregorio, F. Frascella, M. Soster, F. Bussolino, S. Marchiò, F. Geobaldo and F. Giorgis, J. Raman Spectrosc. 43 (2012) 730.

[26] Q. Su, X. Ma, J. Dong, C. Jiang, and W. Qian, ACS App. Mater. Interf. 3 (2011) 1873.

[27] C. S. Rout, A. Kumar and T. S. Fisher. Nanotechnology 22 (39) (2011) 395704.

[28] L. Debarge, J.P. Stoquert, A. Slaoui, L. Stalmans, J. Poortmans, Mat. Sci. Semicon. Process 1 (1998) 281. 
[29] S. M. Haidary, E. P. Corcoles, and N. K. Ali, J. Nanomat. 24 (29) (2012) 830503.

[30] P. Pirasteh, J. Charrier, A. Soltani, S. Haesaert, L. Haji, C. Godon and N. Errien, Appl. Surf. Sci. 253 (2006) 1999.

[31] M. Hiraoui, M. Guendouz, N. Lorrain, A. Moadhen, L. Haji and M. Oueslati, Mat. Chem. Phys. 128 (2011) 151.

[32] H. L. Li, Y. Zhu, D. Xu, Y. Wan, L. Xia, and X. S. Zhao, J. Appl. Phys. 105 (2009) 114307.

[33] T. Sakata, S. Maruyama, A. Ueda, H. Otsuka, and Y. Miyahara, Langmuir 23 (2007) 2269.

[34] Qianqian Su, Xiaoyuan Ma, Jian Dong, Caiyun Jiang, and Weiping Qian ACS Appl. Mater. Interfaces 3 (2011) 1873.

[35] C. Xie, Y. Q. Li, W. Tang and R. J. Newton, J. Appl. Phys. 94 (2003) 6138.

[36] E.C.Y. Li-Chan, S. Nakai, M. Hirotsuka, Blackie Academic \& Professional, London, UK. 1994, 163.

[37] O. J. Bos, J. F. Labro, M. J. Ficher, J. Wilting and L. H. Janssen, J. Bio.Chem. 264 (1989) 953.

[38] Sigma, Product Information, CAS number 9048-46-8, (1997). 